\title{
Comparisons of incidence of spinal and lower extremity deformities according to the physical characteristics between sports major and nonmajor college students
}

\author{
Jangwon Lee* \\ Department of Sports Health Medicine, College of Sports, Jungwon University, Goesan, Korea
}

This research was performed to identify the incidence of spinal and lower extremity deformity and to identify the relationship of the incidence between the physical characteristics. One hundred forty-seven Physical Education major students and 54 nonmajor students participated in this study. Data collecting was performed by questionnaire and visual postural evaluation. The incidences of genu varus $(P<0.00001)$, genu recurvatum $(P=0.0007)$, forward head $(P<0.00001)$, lordosis $(P<0.00001)$, and scoliosis $(P=0.0008)$ were significantly lower in nonmajor students compared to major students. The incidences of genu varus $(P=0.0017)$, leg length discrepancy $(P=0.0015)$, and forward head
$(P=0.005)$ were significantly greater in women than their counterpart. However, in genu recurvatum $(P<0.00001)$, kyphosis $(P=0.0001)$, and lordosis $(P=0.0024)$, the incidences were significantly lower in women. Overweight (body mass index [BMl] $>24.5 \mathrm{~kg} / \mathrm{m}^{2}$ ) students showed significantly high incidence (4.7 times, $P=0.0044$ ) in genu varus compared to students with normal $\mathrm{BMI}$, and revealed significantly low incidence in genu recurvatum $(P=0.0047)$ and protruding abdomen $(P=0.0002)$.

Keywords: Spinal and lower extremity deformity, Major, Body mass index

\section{INTRODUCTION}

Musculoskeletal disorders are one of the most frequent health problem for people around the world. These disorders have great consequences for public health because of their severe impact on body's disability, health care expenses, sick leave (Valkenburg, 1979). About $6 \%$ of the total healthcare costs (Meerding et al., 1998) and 30\% of all sick-leave days are due to musculoskeletal problems (Moncrieff and Pomerleau, 2000).

Recently, research started to demonstrate a significant relationship between physical inactivity and variety of musculoskeletal disorders and health conditions. Several studies reported that regular aerobic exercise reduce the risk of suffering from various health conditions (Jakicic et al., 2003; Ketelhut et al., 2004). With the greater interest of the benefits of physical activity, a more health conscious population expressed interest in exercise. In school surroundings, it is natural that students majoring sports

have greater chance to participate in sport activities than nonmajoring students.

It is well known that regular exercise brings muscle strength and endurance which are two important components of muscular fitness. Diseases and disorders of the musculoskeletal system, such as osteoporosis, osteoarthritis, bone fractures, connective tissue tears, and low back syndrome, are related to physical inactivity and a sedentary lifestyle (Heyward and Gibson, 2014).

However, questions have been raised regarding the incidence of body deformity by participation in sports activities. For example, sport activities with high impact has been found to be a risk factor for sports injuries and deformities of the musculoskeletal system (Kujala et al., 1997).

Agricola et al. (2012) also demonstrated that body deformities are more prevalent in athletes than in nonathletes and proposed that body deformities develops during adolescence and is probably to be affected by high-impact sports practice.

${ }^{*}$ Corresponding author: Jangwon Lee iD http://orcid.org/0000-0002-1086-3323 Department of Sports Health Medicine, College of Sports, Jungwon University, 85 Munmu-ro, Goesan-eup, Goesan 28024, Korea 
Spinal deformity alters normal spine biomechanics leading to global balance and possible detriment to quality of life (Fong et al., 2010). Imbalances of spinal alignment have been reported to relate to postural instability (Ishikawa et al., 2009). Any spinal deformity has been shown to suffer from long-term functional disturbances and earlier onset back pain and disc degeneration than normal individuals. Spinal deformities might be considered to relate to the lower extremities, such as knee or hip flexion and extension positions (Itoi, 1991). However, no study has reported on the relationship between spinal deformities and lower extremities.

Therefore, the purpose of the study was (a) to identify the incidence of each spinal deformity and lower extremity deformity and identify the relationship of the incidence between the deformities and (b) to identify the effects of major and physical characteristics (body mass index [BMI], gender, age, and dominant arm) on the development of 5 spinal deformities (forward head, protruding abdomen, kyphosis, lordodis, and scoliosis) and 4 lower extremity deformities (genu valgus, genu varus, genu recurvatum, and leg length discrepancy).

\section{MATERIALS AND METHODS}

\section{Participants}

One hundred forty-seven sports major students and 54 nonmajor students participated in this study. Among them 133 students were males and 68 students were females. Physical characteristics of the subjects are listed in Table 1.

\section{Data collecting}

All subjects were screened and individuals were removed from the test if they had medical problems such as lumbago and previous lower extremity fracture. Each subject was asked wear pants and shirts only. No socks were permitted for the data collecting. The subjects were asked to answer each question on the questionnaire including college major, age, gender, height, and weight.

Table 1. Physical characteristics of subjects $(n=201)$

\begin{tabular}{lcc}
\hline Characteristic & Major $(n=147)$ & Nonmajor $(n=54)$ \\
\hline Sex & & \\
Male & 102 & 31 \\
Female & 45 & 23 \\
Age $(\mathrm{yr})$ & $22.24 \pm 1.47$ & \\
Height $(\mathrm{cm})$ & $171.71 \pm 0.03$ & \\
Weight $(\mathrm{kg})$ & $67.88 \pm 12.98$ & \\
\hline
\end{tabular}

Values are presented as mean \pm standard deviation.

\section{Experimental procedures}

The visual postural examination of the spine and lower extremity was conducted from anterior, posterior, lateral, and prone positions. From the anterior view, height of the shoulder on both sides was observed. From the posterior view, any sign of scoliosis, genu valgus, genu varus, or genu recurvatum was observed. From the lateral view, any sign of forward head, protruding abdomen, kyphosis, lordosis was observed. From the prone position, observation was performed if there is leg length discrepancy. This procedure was established and validated by Wen et al. (1998).

\section{Statistical analyses}

A logistic regression was used to identify the association of genu valgus, genu varus, genu recurvatum, leg length discrepancy, forward head, protruding abdomen, kyphosis, lordosis, and scoliosis. Independent variables were major and nonmajor, gender, and BMI converted from the height and the weight.

Each spinal and lower extremity deformities was considered as dependent variable in the study. Data were analyzed with IBM SPSS Statistics ver. 20.0 (IBM Co., Armonk, NY, USA) and statistical significance was set at $P<0.05$ for all tests.

\section{RESULTS}

Table 2 shows the result of the relationship of deformity incidence between sport major and nonmajor. According to Table 2, the incidences of genu varus $(P<0.00001)$, genu recurvatum $(P=$ $0.007)$, forward head $(P<0.00001)$, lordosis $(P<0.00001)$, and scoliosis $(P=0.0008)$ were significantly lower in nonmajor students compared to major students to the amount of $91 \%, 76 \%$, $90 \%, 87 \%$, and $73 \%$, respectively.

The relationship of deformity incidence between gender is presented in Table 3. As shown in Table 3, the incidences of genu

Table 2. Relationship of deformity incidence between major and nonmajor

\begin{tabular}{lccc}
\hline Variable & $\begin{array}{c}95 \% \text { Confidence } \\
\text { interval }\end{array}$ & Odd ratio & Pfor trend \\
\hline Genu valgus & - & - & - \\
Genu varus & $0.033-0.246$ & 0.09 & $<0.0001$ \\
Genu recurvatum & $0.085-0.681$ & 0.24 & 0.007 \\
Leg length discrepancy & $0.287-1.034$ & 0.56 & 0.063 \\
Forward head & $0.049-0.209$ & 0.10 & $<0.0001$ \\
Protruding abdomen & $0.441-4.441$ & 1.40 & 0.568 \\
Kyphosis & - & - & - \\
Lordosis & $0.056-0.302$ & 0.13 & $<0.0001$ \\
Scoliosis & $0.105-0.711$ & 0.27 & 0.008
\end{tabular}


Table 3. Relationship of deformity incidence between gender

\begin{tabular}{lccc}
\hline Variable & $\begin{array}{c}\text { 95\% Confidence } \\
\text { interval }\end{array}$ & Odd ratio & Pfor trend \\
\hline Genu valgus & $0.130-1.975$ & 0.506 & 0.327 \\
Genu varus & $1.282-12.524$ & 4.007 & 0.017 \\
Genu recurvatum & $0.005-0.086$ & 0.200 & $<0.0001$ \\
Leg length discrepancy & $1.183-4.591$ & 2.330 & 0.015 \\
Forward head & $0.998-4.211$ & 2.050 & 0.050 \\
Protruding abdomen & - & - & - \\
Kyphosis & $0.021-0.351$ & 0.086 & 0.001 \\
Lordosis & $0.158-0.879$ & 0.373 & 0.024 \\
Scoliosis & $0.279-2.090$ & 0.764 & 0.600 \\
\hline
\end{tabular}

varus $(P=0.0017)$, leg length discrepancy $(P=0.0015)$, and forward head $(P=0.005)$ were significantly greater in women than their counterpart to the amount of $4,2.3$, and 2 times, respectively. However, in genu recurvatum $(P<0.00001)$, kyphosis $(P=$ $0.0001)$, and lordosis $(P=0.0024)$, the incidences were significantly lower in women to the $80 \%, 91.4 \%, 91 \%$, respectively.

Table 4 displays the result of the relationship of deformity incidence according to BMI. As seen in Table 4, students in overweight ([BMI] $\left.>24.5 \mathrm{~kg} / \mathrm{m}^{2}\right)$ showed significantly high incidence (4.7 times, $P=0.0044$ ) in genu varus compared to students with normal BMI, and revealed significantly low incidence in genu recurvatum $(P=0.0047)$ and protruding abdomen $(P=0.0002)$ to the amount of $64.6 \%$ and $79 \%$ each in overweight students.

\section{DISCUSSION}

The result of the study revealed that the incidence of spinal and lower extremity deformities in nonmajoring students showed significantly lower than sport majoring students. This result of the present investigation is consistent with the conclusion by Kujala et al. (1997) and Agricola et al. (2012). It is believed that adolescent with less musculoskeletal maturity may experience a increased risk for more skeletal damage and structural abnormalities when exposed to intense levels of sports activities.

Deformity incidence in women was significantly high in genu varus, leg length discrepancy, and forward head. On the contrary, the incidences of genu recurvatum, khphosis, and lordosis were significantly lower in women compared to their counterparts. These differences in compensatory mechanisms should be considered when evaluating and planning spinal and lower extremity deformities for further studies.

Genu varum is a physical deformity marked by bowing of the leg. One of the risk factors of this musculoskeletal alignment is
Table 4. Relationship of deformity incidence according to body mass index (established abnormal when over 24.5)

\begin{tabular}{lccc}
\hline Variable & $\begin{array}{c}\text { 95\% Confidence } \\
\text { interval }\end{array}$ & Odd ratio & Pfor trend \\
\hline Genu valgus & $0.415-6.342$ & 1.623 & 0.486 \\
Genu varus & $1.042-20.824$ & 4.659 & 0.044 \\
Genu recurvatum & $0.127-0.987$ & 0.354 & 0.047 \\
Leg length discrepancy & $0.704-2.586$ & 1.350 & 0.366 \\
Forward head & $0.411-1.543$ & 0.796 & 0.499 \\
Protruding abdomen & $0.079-0.558$ & 0.210 & 0.002 \\
Kyphosis & $0.159-1.663$ & 0.514 & 0.266 \\
Lordosis & $0.515-3.168$ & 1.277 & 0.597 \\
Scoliosis & - & - & - \\
\hline
\end{tabular}

stress on the knee joint such as with exercise. Chantraine (1985) hypothesized that the stress and strain on a joint caused by regular practicing of an intensive sport during adolescence may lead to a growth deformity. It is speculated that obese students participating sports activities to reduce the body weight may encounter genu varum before weight loss.

\section{CONFLICT OF INTEREST}

No potential conflict of interest relevant to this article was reported.

\section{REFERENCES}

Agricola R, Bessems JH, Ginai AZ, Heijboer MP, van der Heijden RA, Verhaar JA, Weinans H, Waarsing JH. The development of Cam-type deformity in adolescent and young male soccer players. Am J Sports Med 2012;40:1099-1106.

Chantraine A. Knee joint in soccer players: osteoarthritis and axis deviation. Med Sci Sports Exerc 1985;17:434-439.

Fong DY, Lee CF, Cheung KM, Cheng JC, Ng BK, Lam TP, Mak KH, Yip PS, Luk KD. A meta-analysis of the clinical effectiveness of school scoliosis screening. Spine (Phila Pa 1976) 2010;35:1061-1071.

Heyward VH, Gibson AL. Advanced fitness assessment and exercise prescription. 7th ed. Champaign (IL): Human kinetics; 2014.

Ishikawa Y, Miyakoshi N, Kasukawa Y, Hongo M, Shimada Y. Spinal curvature and postural balance in patients with osteoporosis. Osteoporos Int 2009;20:2049-2053.

Itoi E. Roentgenographic analysis of posture in spinal osteoporotics. Spine (Phila Pa 1976). 1991;16:750-6.

Jakicic JM, Marcus BH, Gallagher KI, Napolitano M, Lang W. Effect of exercise duration and intensity on weight loss in overweight, sedentary 
women: a randomized trial. JAMA 2003;290:1323-1330.

Ketelhut RG, Franz IW, Scholze J. Regular exercise as an effective approach in antihypertensive therapy. Med Sci Sports Exerc 2004;36:4-8.

Kujala UM, Taimela S, Oksanen A, Salminen JJ. Lumbar mobility and low back pain during adolescence. A longitudinal three-year follow-up study in athletes and controls. Am J Sports Med 1997;25:363-368.

Meerding WJ, Bonneux L, Polder JJ, Koopmanschap MA, van der Maas PJ. Demographic and epidemiological determinants of healthcare costs in Netherlands: cost of illness study. BMJ 1998;317:111-115.
Moncrieff J, Pomerleau J. Trends in sickness benefits in Great Britain and the contribution of mental disorders. J Public Health Med 2000;22:5967.

Valkenburg HA. Epidemiologisch Preventief Onderzoek Zoetermeer(EPOZ). 5th progress repost, part 4. Rotterdam: Erasmus Universiteit Rotterdam; 1979.

Wen DY, Puffer JC, Schmalzried TP. Injuries in runners: a prospective study of alignment. Clin J Sport Med 1998;8:187-194. 